\title{
HIGH EFFICIENT ROTARY HULLER MACHINE
}

\author{
S.R. Kulkarni \\ Department of ME \\ Hirasugar Institute of Technology, \\ Nidasoshi591236, Karnataka, India
}

\author{
S.A. Goudadi \\ Department of ME \\ Hirasugar Institute of Technology, \\ Nidasoshi591236, Karnataka, India
}

\begin{abstract}
Many developments have been taking place to improve the quality of the existing product. Customers are always looking for the good quality product at an affordable cost. It is equally important to maintain the nutrients while processing the food items. In this paper the focus has been given to develop a new product which could remove the chaff and to obtain the powder if the grain. Machine operates by the use of gravitational force and electricity. The cost of the machine is also less compared with other conventional machines. The machine can be used for mixing and grinding of all types of grocery items. It can process ragi, wheat and rice etc, also for grinding herbal and non herbal products for medicines.
\end{abstract}

Keywords - Grains, De-husking, Pulverize, Nutrients, Flavor.

\section{INTRODUCTION}

The outer husk of the grains could be removed by an agricultural machine called as huller; the same machine can be used to obtain powder of the grains. Since old era many developments have been taking place to innovate new techniques to hull seeds or grains. Traditional method of hulling grains consumes more human power and time. Grinder mill is not affordable to the most common people as it is more expensive. Moreover there is a danger of generating high heat due to the high friction which may result in to the loss of flavor and risk of chemical contamination in medical plants and roots. Rotary huller is an efficient machine which increases the mechanization in rural areas. The machine is very easy to operate, designed especially for the women who can do the job of hulling without body ache as it eliminates much drudgery of manual hulling. The machine takes care of the expectations of the end users who believe in the best quality of a product which is packed by hand. In this machine the amount of heat generated during the processing operation is much reduced and also the original flavor of the grains is maintained,

\section{LITERATURE SURVEY}

Padghan. K. K et al. (2014) reviewed on human power flywheel motor. They have developed a man -machine system model consisting of pedal driven fly wheel motor, transmission shaft and input shaft of process unit [1]. Umesh Bokade, et al. (2013) designed a model which uses renewable source of energy to convert the saline water into pure water. They have used bicycle-drive mechanism with humanpowered flywheel motor, speed increasing gearings, spiral jaw clutch and torque increasing gearing unit in their model [2]. Pitale. A.K. et al. (2012) reviewed upon the extensive usage of fly wheel applications in all the works done manually [3]. Hussain. H.A. et al. (2014) designed a bicycle integrated pipe bending mechanism. the pipe with $25 \mathrm{~mm}$ diameter and thickness of about $2 \mathrm{~mm}$ can be bent using the mechanism. The bent pipes are used in various applications like bicycle handle, fluid passages and exhaust pipes etc [4]. Zoeb khan.et al. (2015) have designed and fabricated human powered wood cutting tool to ensure smooth cutting during operation. The equipment uses no electric power, light weighted and portable machine [5]. Bahaley S.G. et al. (2012) carried out performance analysis on pedal powered multipurpose machine. The machine can lift water up to 10 meter also can generate 14 Volts and 4 Ampere current [6]. Sreejith K. et al. (2014) conducted experiments on the pedal driven hacksaw. The machine can cut plywood around up to $17 \mathrm{~mm}$ depth when one cycle of stroke covers $100 \mathrm{rpm}$ [7]. Adeleke.S et al, (2017) designed a small scale hulling machine for improved wet processed coffee, the machine was cost effective in running, affordable and runs on 3HP petrol engine [8]. Devaraju R.B et al. (2018) produced pedal operating rotary huller machine. The machine was useful for hulling parchment and dry cherry coffee. This was highly efficient machine with low power consumption and higher throughput [9]. Ikechukwu Celestine Ugwuoke et al. (2014) designed and fabricated a manually operated roasted groundnut seeds peeling machine. They have used transmission mechanism to reduce the effort to the drive systems. A special chamber was designed reduced the amount of breakages during peeling. The capacity of peeling was $5.4 \mathrm{Kg} / \mathrm{hr}$ for roasted groundnut seeds [10]. Santosh Mangave et al. (2015) designed a Portable Groundnut Sheller Machine. The machine was useful for shelling only the dry pods and the machine could be used for domestic applications [11]. Roshan P Ghodkhande et al. (2015) published a research paper on design and modification of ground-nut decorticator. In their work they focused upon the drawbacks for traditional methods of ground nut decorticator. 
The machine was designed to utilize the low power and was affordable to the needy masses of people. The design was modified in such a way that the seeds not to get damaged and could be utilized for plantation [12]. Khodabakhshian $\mathrm{R}$ et al. (2010) published a research paper on systematic design of a pistachio hulling machine. In their work they have designed an innovative machine that could do hulling, washing and dehydrating processes simultaneously. The principle of centrifugal force was used for the purpose of pistachio hulling [13]. Oluwole. F. A et al (2007) published a research paper on development and performance evaluation of impact bambara groundnut sheller, their work represents design, construction and evaluation of centrifugal bambara groundnut sheller machine. They have examined the performance by using factorial design. Finally they found that no unshelled pods and as the machine was high efficient [14].

\section{CONSTRUCTION AND WORKING PRINCIPLE}

The huller machine is constructed using a circular disc, plungers in six hollow cylinders, a center shaft with chain wheel arrangement, a drive shaft with pulley arrangement, a support frame and if required an electric motor (three phase 1 HP). Each side of the circular disc is fixed with the hollow cylinders with a plunger each in to them. One end of the hollow cylinder is closed and the other end is opened so that loading and unloading of the grains could be easy before and after the hulling operation. The center shaft passes through the axis of the disc, with pulley arrangement at the one end of shaft. The drive shaft is fixed to the side of frame. The belt drive is used to transmit the power from electric motor to the drive shaft and another belt drive is used to transmit the power from drive shaft to the center shaft. The robust frame is used to support the various components in the right position and all the rotational components are supported with the help of bearing block.

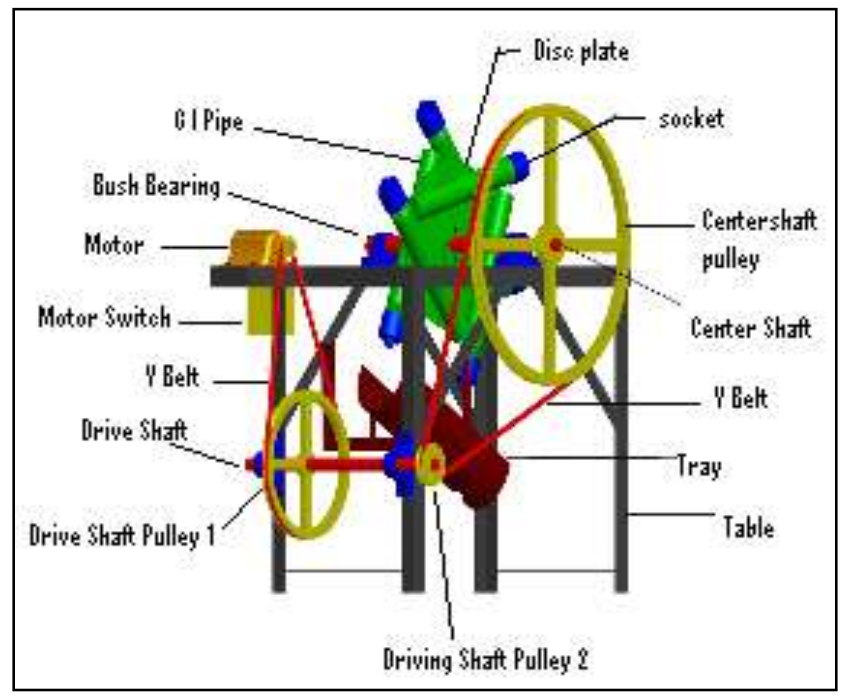

Fig. 1. Design of rotary huller machine
Rotary huller uses the principle of the inherent gravitational force of falling bodies to do the hulling with or without using any electricity or fuel. This machine can be operated manually as well as electrically. It uses the concepts of gravitational force and kinetic energy. When the circular disc is rotated by hand or by an electric motor, the plungers pulverize the material inside the hollow tube. This strikes the ends of hollow cylinder twice on one complete 360 degree rotation. On the first cycle of rotation from 0 to 180 degrees, when the hollow cylinder reaches a 90 degree position with respect to the center shaft, plunger strikes one end of the hollow cylinder due to the gravitational pull. On the second cycle of rotation from 180 - 360 degrees, it strikes other end of the hollow cylinder. The momentum developed by the plunger during its travel raises impact force. The impact force is sufficient to bring the grains in to the powder form. The Plunger fall freely due to the gravitational pull the "speed of the rotation is kept at a pace that does not overshoot the gravitational pull over the plunger" (i.e. speed of rotation must be less than escape velocity).

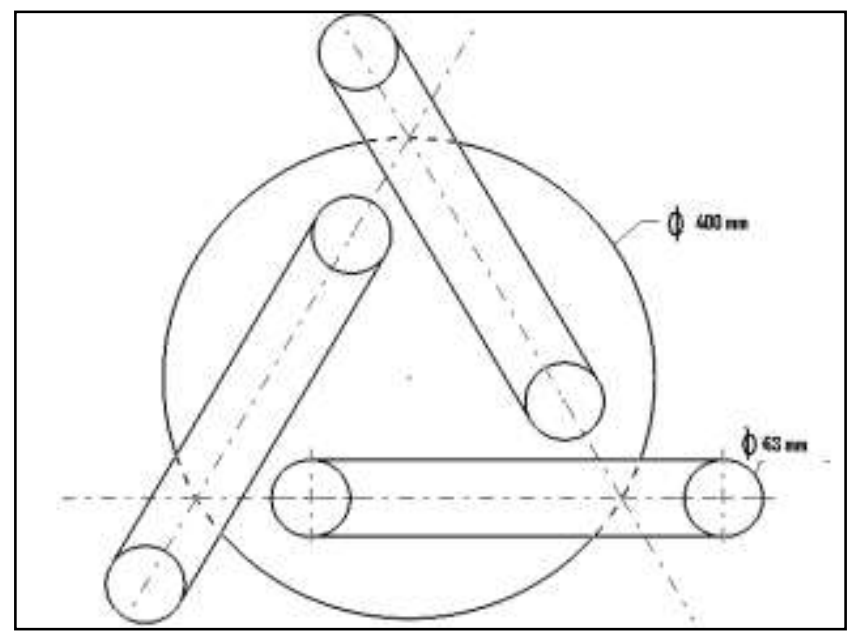

Fig. 2. Circular disc with cylinders

\section{IV.COMPONENT DETAILS}

The following table shows the components used for constructing the huller machine.

Table -1 Component Details

\begin{tabular}{|c|l|c|l|}
\hline S.N & \multicolumn{1}{|c|}{ Components } & Materials & \multicolumn{1}{c|}{ Dimensions } \\
\hline 1. & Six hallow tubes & GI & $\begin{array}{l}\text { 63mm 458mm in } \\
\text { length each }\end{array}$ \\
\hline 2. & Disc & MS & $\begin{array}{l}\text { 6mm thick with } \\
\text { 200mm in radius }\end{array}$ \\
\hline 3. & $\begin{array}{l}\text { Two shafts; } \\
\text { i. Center shaft }\end{array}$ & Hard MS & $\begin{array}{l}\text { 40mm diameter \& } \\
\text { required length. } \\
\text { Variable diameter \& } \\
\text { length as required by } \\
\text { pulley arrangement. }\end{array}$ \\
\hline $4 . \quad$ Drive shaft & Plungers. [6] & Hard MS MS & $\begin{array}{l}\text { 36mm diameter \& } \\
\text { 150mm length. }\end{array}$ \\
\hline
\end{tabular}


International Journal of Engineering Applied Sciences and Technology, 2019

Vol. 4, Issue 3, ISSN No. 2455-2143, Pages 137-141

Published Online July 2019 in IJEAST (http://www.ijeast.com)

\begin{tabular}{|c|l|c|l|}
\hline 5. & $\begin{array}{l}\text { Pulley's with belt drive } \\
\text { i. Pulley at motor shaft. } \\
\text { ii. Pulley at drive shaft. } \\
\text { ii. Pulley at center shaft. }\end{array}$ & $\begin{array}{l}\text { CI } \\
\text { CI }\end{array}$ & $\begin{array}{l}\text { CI } \\
\text { diammeters. } \\
\text { diameter. } \\
660 \mathrm{~mm} \text { diameter. }\end{array}$ \\
\hline 6. & Bush bearings. & Babbit & $\begin{array}{l}\text { As per shaft diameter } \\
\text { requirement. }\end{array}$ \\
\hline 7. & 12 enclosures [caps] & GI & $\begin{array}{l}\text { As per diameter of } \\
\text { hallow tubes. }\end{array}$ \\
\hline 8. & Frame & MS & As per requirement. \\
\hline 9. & Motor & $* * *$ & $1 \mathrm{HP}$ \\
\hline
\end{tabular}

\section{V.CALCULATIONS}

4.1) Speed Reduction from Drive Shaft to Center Shaft

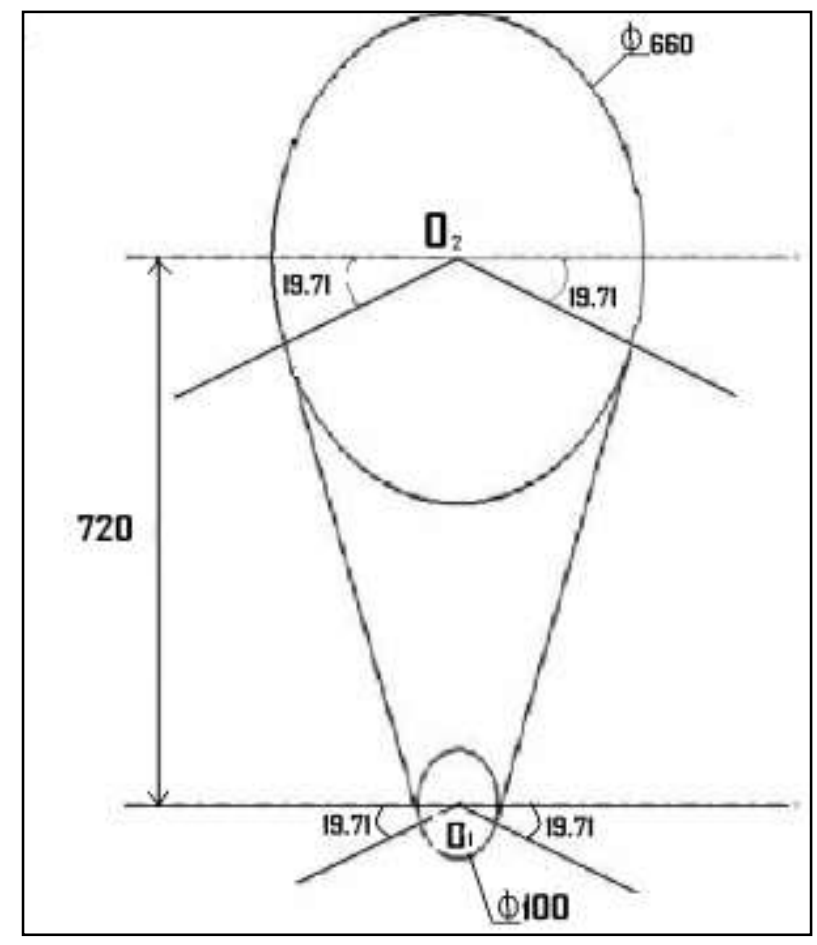

Fig. 3. Drive shaft and center shaft with $\mathrm{V}$ belt

\section{a) Length of belt}

$\mathrm{L}=\pi(\mathrm{r} 1+\mathrm{r} 2)+2 \mathrm{c}+[(\mathrm{r} 1-\mathrm{r} 2) 2 / \mathrm{c}]$

$\mathrm{L}=\pi(50+330)+2 \times 750+[(50-330) 2 / 750]$

$\mathrm{L}=2798.33 \mathrm{~mm}$

\section{b) Velocity ratio}

$\mathrm{n} 1 / \mathrm{n} 2=\mathrm{d} 2 / \mathrm{d} 1$

$144 / \mathrm{n} 2=660 / 100$

$\mathrm{n} 2=21.81 \mathrm{rpm}$

Where,

$\mathrm{n}_{1}=$ speed of the driver in $\mathrm{rpm}$

$\mathrm{n}_{2}=$ speed of the driven in rpm

$\mathrm{d}_{1}=$ diameter of the driver in $\mathrm{mm}$

$\mathrm{d}_{2}=$ diameter of the driven in $\mathrm{mm}$
4.2) Speed reduction from motor to drive shaft

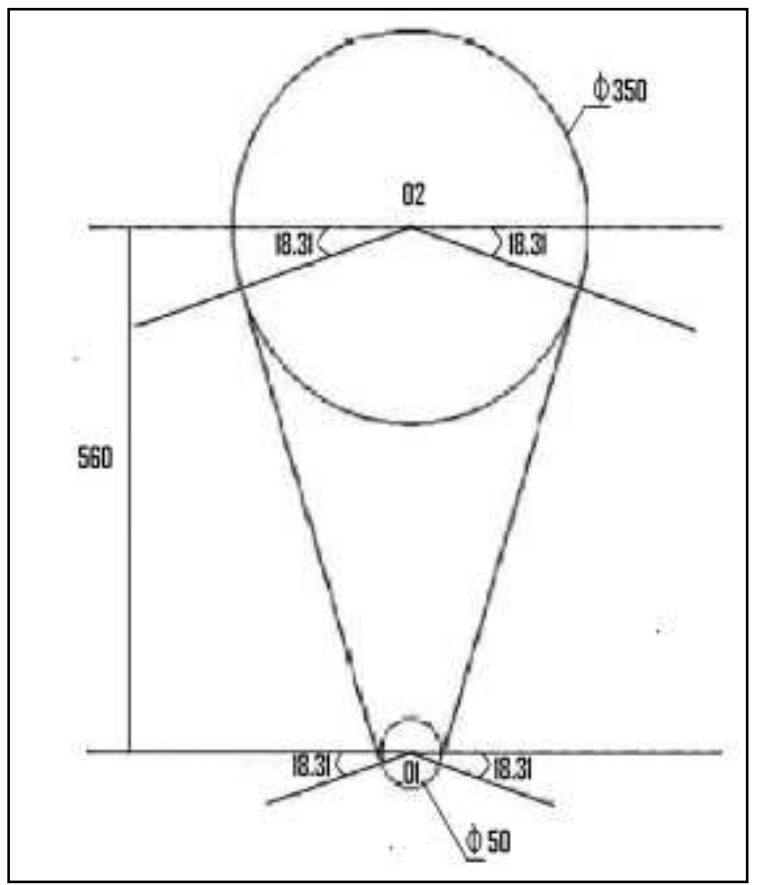

Fig. 3. Drive shaft and motor shaft with V belt

\section{a) Length of belt}

$$
\begin{gathered}
\mathrm{L}=\pi(\mathrm{r} 1+\mathrm{r} 2)+2 \mathrm{c}+[(\mathrm{r} 1-\mathrm{r} 2) 2 / \mathrm{c}] \\
\mathrm{L}=\pi(17.5+175)+2 \times 560+[(17.5-175) 2 / 560] \\
\mathrm{L}=1769 \mathrm{~mm}
\end{gathered}
$$

\section{b) Velocity ratio}

$$
\begin{aligned}
& \mathrm{n} 1 / \mathrm{n} 2=\mathrm{d} 2 / \mathrm{d} 1 \\
& 1440 / \mathrm{n} 2=350 / 35 \\
& \mathrm{n} 2=144 \mathrm{rpm}
\end{aligned}
$$

\section{EXPERIMENTAL RESULTS}

The experiments have been conducted by using soft and hard grains. The hulling time considered was 1 hour. The following results were obtained.

Table -2 Experiment Result

\begin{tabular}{|c|c|c|c|}
\hline S. No & Materials & Properties & Hulling rate \\
\hline 1. & Jowar & Hard grains & $1.2 \mathrm{~kg} / \mathrm{hour}$ \\
\hline 2. & Wheat & Hard grains & $1.2 \mathrm{~kg} / \mathrm{hour}$ \\
\hline 3. & Rice & Hard grains & $1.2 \mathrm{~kg} / \mathrm{hour}$ \\
\hline 4. & Ground nut beans & Soft grains & $4 \mathrm{~kg} /$ hour \\
\hline 5. & Spices & Soft grains & $4 \mathrm{~kg} /$ hour \\
\hline 6. & Rice de-husking & Hard grains & $6 \mathrm{~kg} /$ hour \\
\hline
\end{tabular}




\section{International Journal of Engineering Applied Sciences and Technology, 2019 Vol. 4, Issue 3, ISSN No. 2455-2143, Pages 137-141 \\ Published Online July 2019 in IJEAST (http://www.ijeast.com)}

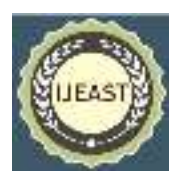

From the experimental results it is seen that since comparatively being hard grains the hulling rate for jowar, wheat and rice is almost the same. Ground nut beans and spices comparatively the soft grains, so the hulling rate is higher that is $4 \mathrm{~kg} / \mathrm{hr}$. The machine removes more easily the outer layer of the rice (de-husking) more easily. So the rate of de-husking the rice is $6 \mathrm{~kg} / \mathrm{hr}$. Apart from these grains the spices which have medical values could also be de-husked by which original flavor and constituents could be maintained.

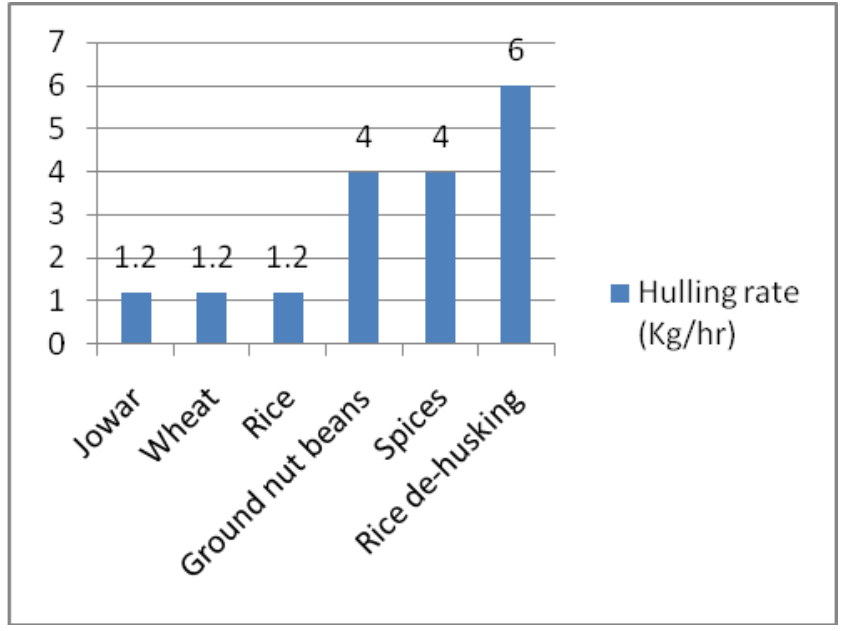

Fig. 4. Hulling rate $(\mathrm{Kg} / \mathrm{hr})$

\section{CONCLUSION}

In the final analysis the production efficiency of this machine is good as shown in the experimental results. The rate of hulling for jowar, wheat and rice found to be the same that is $1.2 \mathrm{Kg} / \mathrm{hr}$. For the soft grains like ground nut beans and spices the hulling rate was found to be $4 \mathrm{Kg} / \mathrm{hr}$. The powder obtained from this machine is fine and without losing any medicinal properties and flavors due to heat generated as in case of conventional flour mills and hence life time of human can be increased. The literature survey concludes the vast coverage of rotary huller machines as a power source to daily household and domestic applications. The modifications could be found as an interesting subject for research and experimentation. The exhaustive survey shows the applications of rotary huller machine as an alternative to conventional energy system and could be found more suitable where lack of energy is experienced.

\section{ACKNOLEDGEMENT}

We thank our beloved principal Dr. Kamate. S. C. for his valuable suggestions. We would like to express our sincere gratitude to the head of the Mechanical Engineering Department Dr. Shrigiri. B. M. for his timely support in the completion of this research work. We thank Dr. Ambiger. C. I. professor from Addis Ababa University, Ethiopia for his valuable suggestions in writing the manu script. We also thank anonymous reviewers for their insights.

\section{REFERENCE}

[1] Padghan. K. K, Pitale A. K, Modak J.P, Narkhedkar A.P. (2014) -Human Powered Flywheel Motor - A Review, International Journal of Engineering Trends andTechnology (IJETT), Volume 8, DOI: 10.14445/ 22315381 / IJETT-V8 P202.

[2] Umesh Bokade, Zakiuddin Syed Kazi and Girish D Mehta (January 2013) -Design And Development of Manually Energized Water Distillation Device, International Journal of Mechanical Engineering and Robotics Research (IJMERR), ISSN 2278 - 0149, Vol.2, No. 1.

[3] Pitale. A. K, Hatwalne. P. A. (November 2012) -A Review on - Flywheel Motor, International Journal of Engineering Science and Innovative Technology (IJESIT), Volume 1, Issue 2. pp 190-193

[4] Hussain. H.A, M.Sohail Pervez, Md. Naushad Alam, Ganorkar. Atul. P. (2014) -Design and Development of Bicycle Integrated Pipe Bending Machine. Journal of Mechanical and Civil Engineering (IOSR-JMCE) eISSN: 2278-1684, p-ISSN: 2320-334X, , pp 24-28.

[5] Zoeb khan, Sushil Dopekar (2015)-Design and Fabrication of Human Powered Wood Cutting machine, International Journal on Recent and Innovation Trends in Computing and Communication(IJRITCC) ISSN: 2321-8169 Volume: 3 Issue: 2, 072-074, pp 72-74

[6] Bahaley. S. G, Dr. Awate. A.U and Saharkar S.V. (July -2012) - Performance Analysis of Pedal Powered Multipurpose Machine, International Journal of Engineering Research \& Technology (IJERT) Vol. 1 Issue 5, ISSN: 2278-0181.

[7] Sreejith K, Aravind K, Danie Davis, Farish K. A. George Johnson (July 2014) - Experimental Investigation of Pedal Driven Hacksaw, Research Inventy: International Journal of Engineering And Science (IJES), Vol.4, Issue 7, pp 01-05 ISSN (e): 2278-4721, ISSN (p):2319-6483.

[8] Adeleke.S. A, Olukunle. O.J., Olaniran. J. A, Famuyiwa.B. S (2017) - Design of A Small-Scale Hulling Machine For Improved Wet-Processed Coffee, International Journal of Scientific \& Technology Research, Volume 6, Issue 08, ISSN 2277-8616, pp 391-397. 
[9] Devaraju R.B, Bheemappa. Shiddappa. Gaji (2018) Pedal Operating Coffee Huller Machine, Journal of Emerging Technologies and Innovative Research (JETIR), Volume 5, Issue 1, ISSN 2349-5162, pp 382386.

[10] Ikechukwu Celestine Ugwuoke, Olawale James Okegbile, Ibukun Blessing Ikechukwu, Robert Temitope John (2014) - Design and Development of Manually Operated Roasted Groundnut Seeds Peeling Machine, International Journal of Recent Development in Engineering and Technology (IJRDET), Volume 2, Issue 4, ISSN 2347 - 6435, pp 30-33.

[11] Santosh Mangave, Bhagyesh Deshmukh (2015)Design of a Portable Groundnut Sheller Machine, International Journal of Mechanical Engineering and Information Technology (IJMEIT) Volume 3, Issue 4, ISSN-2348-196x, pp 1125-1129.

[12] Roshan P Ghodkhande, Nilesh D Dhote, Sandip J Kadam (2015)- Design and Modification of GroundNut Decorticator, International Journal of Innovative Research in Computer and Communication Engineering(IJIRCCE), Vol. 3, Issue 12, ISSN(Online): 2320-9801 ISSN (Print): 2320-9798, DOI: 10.15680/IJIRCCE.2015. 0312016, pp 1215012154.

[13] Khodabakhshian R, Bayati M.R, Shakeri M., Khojastepour M (2010)- Systematic Design of a Pistachio Hulling Machine, Asian International Journal of Science and Technology in Production and Manufacturing Engineering (AIJSTPME), Vol. 3, Issue 2, pp 7-13.

[14] Oluwole. F.A, Abdulrahim. A T, Oumarou M.B. (2007) - Development and performance evaluation of impact bambara groundnut sheller, Agricultural Engineering international: The CIGR Journal of scientific Research and Development Manuscript, Issue 21, Vol.3, pp 269-274. 